\title{
Big Data and Big Cities: The Promises and Limitations of Improved Measures of Urban Life
}

\section{Citation}

Glaeser, Edward L., Scott Duke Kominers, Michael Luca, and Nikhil Naik. "Big Data and Big Cities: The Promises and Limitations of Improved Measures of Urban Life." Economic Inquiry 56, no. 1 (January 2018): 114-137. (Originally Harvard Business School Working Paper, No. 16-065, November 2015.J

\section{Published Version}

https://doi.org/10.1111/ecin.12364

\section{Permanent link}

http://nrs.harvard.edu/urn-3:HUL.InstRepos:24009688

\section{Terms of Use}

This article was downloaded from Harvard University's DASH repository, and is made available under the terms and conditions applicable to Open Access Policy Articles, as set forth at http:// nrs.harvard.edu/urn-3:HUL.InstRepos:dash.current.terms-of-use\#OAP

\section{Share Your Story}

The Harvard community has made this article openly available.

Please share how this access benefits you. Submit a story.

\section{Accessibility}




\section{Big Data and Big Cities: The Promises and Limitations of Improved Measures of Urban Life}

Edward L. Glaeser Michael Luca
Scott Duke Kominers

Nikhil Naik

Working Paper 16-065 


\section{Big Data and Big Cities: The Promises and Limitations of Improved Measures of Urban Life}

Edward L. Glaeser

Harvard University

Michael Luca

Harvard Business School
Scott Duke Kominers

Harvard Business School

Nikhil Naik

MIT Media Lab

Working Paper 16-065 


\title{
Big Data and Big Cities: The Promises and Limitations of Improved Measures of Urban Life
}

\author{
Edward L. Glaeser ${ }^{1,2,3} \quad$ Scott Duke Kominers ${ }^{1,3,4,5} \quad$ Michael Luca $^{5} \quad$ Nikhil Naik $^{6}$
}

\begin{abstract}
New, "big" data sources allow measurement of city characteristics and outcome variables higher frequencies and finer geographic scales than ever before. However, big data will not solve large urban social science questions on its own. Big data has the most value for the study of cities when it allows measurement of the previously opaque, or when it can be coupled with exogenous shocks to people or place. We describe a number of new urban data sources and illustrate how they can be used to improve the study and function of cities. We first show how Google Street View images can be used to predict income in New York City, suggesting that similar image data can be used to map wealth and poverty in previously unmeasured areas of the developing world. We then discuss how survey techniques can be improved to better measure willingness to pay for urban amenities. Finally, we explain how Internet data is being used to improve the quality of city services.
\end{abstract}

\footnotetext{
${ }^{1}$ Department of Economics, Harvard University.

${ }^{2}$ John F. Kennedy School of Government, Harvard University.

${ }^{3}$ National Bureau of Economic Research.

${ }^{4}$ Harvard Society of Fellows, Center for Research on Computation and Society, and Program for Evolutionary Dynamics.

${ }^{5}$ Harvard Business School.

${ }^{6}$ MIT Media Lab.
}

We would like to acknowledge helpful comments from Andy Caplin, William Kominers, and Mitchell Weiss. E.L.G. acknowledges support from the Taubman Center for State and Local Government; S.D.K. acknowledges support from the National Science Foundation (grants CCF-1216095 and SES-1459912), the Harvard Milton Fund, the Wu Fund for Big Data Analysis, and the Human Capital and Economic Opportunity Working Group (HCEO) sponsored by the Institute for New Economic Thinking (INET); and N.N. acknowledges support from The MIT Media Lab consortia. Comments are welcome and may be sent to eglaeser@harvard.edu, kominers@fas.harvard.edu, mluca@hbs.edu, and naik@mit.edu. 


\section{Introduction}

Historically, most research on urban areas has relied on coarse aggregate statistics and smaller-scale surveys. Over the past decade, however, digitization of records, expansion of sensor networks, and the computerization of society has produced a wealth of city data at high temporal frequencies and low levels of spatial and temporal aggregation.

The "big data" revolution will fundamentally change urban science. Big data turns a cross-section of space into living data, offering a broader and finer picture of urban life than has ever been available before. Moreover, in combination with predictive algorithms, big data may allow us to extrapolate outcome variables to previously unmeasured parts of the population. Nevertheless, classical issues of causal inference remainbig data rarely solves identification problems on its own.

For answering classical questions of social science-such as understanding the impact and mechanisms of urban growth, and valuing urban amenities and policies-big data becomes powerful once it is combined with exogenous sources of variation. In urban contexts, the two key exogenous variation sources are "shocks to places" and "shocks to people"; the former consist of high-frequency events that affect geographic regions (e.g., the opening of a million dollar plant; see Greenstone et al. (2010)), while the latter consist of high-frequency events that affect geographic regions within cities (e.g., the Moving to Opportunity (MTO) experiment; see Katz et al. (2001) and Chetty et al. (2015)).

Big data is also improving city management. By making their operations more data-driven, cities can finetune regulations, improve the allocation of scarce resources, and forecast future needs. Crucially, for many urban data interventions, simply being able to predict outcomes or characteristics is valuable on its ownmany practical problems in cities do not directly require causal inference. Moreover, many data-driven interventions are scalable; hence, expansion of data collection and digitization efforts across cities attracts entrepreneurship and innovation.

In Section 2 of this paper, we discuss four questions at the heart of urban social science:

- How does urban development influence the economy?

- How does the physical city interact with social outcomes?

- How much do people value urban amenities?

- How can public policy improve the quality of physical space?

For each question, we highlight how new data sources may improve research by providing improved measurements, and/or new outcome variables of interest. All policy analysis is limited in the scope of outcomes that can be considered; by providing a broad, finely measured snapshot of urban life, big data can enable assessment of policy impacts across new outcome dimensions. And big data is often available at high fre- 
quencies, enabling researchers to measure policies' effects in real time.

We caution throughout, however, that finer measurement can sometimes make inference worse-not betterbecause the selection problems become more severe at the block- or building-level. The strongest case for using big data to assess economic outcomes in cities is when fine geography can be matched with longitudinal data and random events that are tied to a particular locale; in those settings, big data can enable researchers to examine whether there is a treatment effect on people who are close to the random event, no matter where they move.

In Section 3, we show how big data sources can facilitate measurement when government economic statistics are lacking. We use a computer-based visual recognition technique to form a prediction model linking income with Google Street View imagery across New York City block groups. We then show that this prediction model has a $.77 R^{2}$ when used to predict income out-of-sample in New York City and a $.71 R^{2}$ when used to predict income out-of-sample in Boston. Our illustration here suggests that image corpora may provide a key to mapping wealth and poverty in previously unmeasured areas of the developing world. This approach could be used to extrapolate GPS-coded income surveys to much larger populations through image analysis. It should also be possible to provide new insight into the extent of segregation. By tracking changing images over time, computer vision can provide new ways to evaluate the effects of policies as well. More generally, combining big data sources like imagery with predictive methods can be used to "fill in the blanks" in a variety of smaller-sample data sources useful for urban economics. ${ }^{1}$

Section 4 turns to urban surveys and contingent valuation. Typically, contingent valuation has been used for environmental amenities - a context in which it has been disparaged by economists because of nonfamiliarity and non-instrumental preference problems (Hausman (2012)). We believe that housing price hedonics are the best tool for examining how homeowners value local amenities. Nevertheless, there are many urban amenities that bring benefits for people who do not live nearby ${ }^{2}$; for such amenities, survey techniques may be the only way to estimate valuations. We propose two means of improving accuracy of contingent valuation surveys in the urban domain: making choices comparable and and compatible with personal experience. Researchers should not ask subjects to compare an urban park to tax receipts; rather, they should compare one urban park with another equally appealing use of public funds, such as early childhood education slots or increased sidewalk greenspace. Additionally, surveys should be structured in ways that do not ask subjects to make judgments that are completely foreign to their real-world experiences. Few people have ever had to decide whether to spend ten million dollars on an urban park. However, people choose where they walk on a daily basis. Thus, rather than asking people about monetary valuations for

\footnotetext{
${ }^{1}$ For example, if researchers have image time-series, then it will be possible to examine whether a new road increases economic prosperity in the region (for a related example, see Naik et al. (2015)). Image data will never on their own enable us to see whether a treatment impacts people or just place — since images do not indicate whether the occupants of particular areas have changed-but imagery provides rich outcome variables at lower levels of aggregation than were previously available.

${ }^{2}$ For example, Central Park presumably benefits even those New Yorkers who do not live on Fifth Avenue or Central Park West, both by providing leisure space and by improving air quality.
} 
parks, it may be preferable to gauge demand by asking whether people would walk a block to have the chance of walking through the park instead of a more standard streetscape.

Finally, Section 5 looks at the connection between big data and government service provision. There are many areas in which public services improve with information, including ensuring sanitary conditions in restaurants and hotels, targeting repairs of potholes, identifying struggling students, or deciding sentences for convicted criminals; in many of these contexts, machine learning can be used to make urban resource allocation more efficient. Complaints on Tripadvisor or Yelp, for example, can be used to guide public inspections via predictive algorithms. Big data thus provides a means of improving city services—often without explicitly requiring causal inference. ${ }^{3}$ Generalizing from the preceding examples, we provide a taxonomy of new data sources that can be used to improve both the measurement of urban quality of life and the allocation of scarce resources.

\section{Urban Questions and Big Data}

In this section, we review four key questions of urban science, and discuss how big data can be used to help answer each. None of the questions we discuss here are new-we focus on how big data helps us approach classical questions in new ways. Throughout, we will differentiate between cases where big data just means better measurement and cases where big data offers the possibility of better identification as well.

First, we examine the core question of urban economics: how urbanization and the physical city impact productivity. Then, we consider broader questions of urban social science-how the physical city impacts to non-economic outcomes like quality of life, social connections, and leisure activities. Next, we turn to the closely related question of how people value changes in the city. Finally, we turn to practice, examining how new data can improve the quality of urban services.

\section{How does urban development influence the economy?}

The literatures in urban and regional economics have focused first and foremost on identifying the determinants of local productivity. Perhaps the most central question is whether there are agglomeration economies (e.g., Ciccone and Hall (1996)): Do increases in density increase productivity? Perhaps most policy-relevant is the impact of infrastructure (see, e.g., Gramlich (1994)): Do infrastructure investments deliver large economic returns? A third urban economics literature (see, e.g., Rauch (1993); Moretti (2004)) examines human capital spillovers: Does having educated neighbors make you more productive?

\footnotetext{
${ }^{3}$ Our computer vision analysis in Section 3 shows that machine learning methods can be used to extrapolate dependent variables for use in economic analysis. The case of city resource allocation provides a second instance in which applying machine learning algorithms to big data from cities can be directly useful—even without new sources of variation.
} 
In the case of productivity outcomes, big data typically means administrative income data available at fine geographic frequencies (and sometimes disaggregated temporal frequencies as well). Administrative Internal Revenue Service (IRS) data, for example, provides address-level information on income. Longitudinal Business Database data provides address-level data on firm productivity and revenues. Other sources, such as credit card companies, can provide urban business sales data that is disaggregated across both time and space.

Even very fine data, however, does little on its own. Big data is most valuable when it improves causal inference, typically through combination with exogenous shocks. ${ }^{4}$

Typically, the underlying cross-sectional relationships are clear. A one log point increase in density at the metropolitan area (or zip code) level is associated with about a .06 log point increase in productivity or wages (Glaeser and Gottlieb (2008)). The human capital spillover relationships are even stronger. The hard question is whether these cross-sectional relationships reflect causality or unobserved heterogeneity across people and/or across places. ${ }^{5}$

From a historical perspective, unobserved place-based heterogeneity is likely to be quite significant. Nineteenth century New York grew great because its harbor and water-borne access into the American continent provided huge productive advantages not only to traders, but also to manufacturers who benefited from lower transportation costs. The coal mines outside of Pittsburgh provided productive advantages to the steel factories of Andrew Carnegie, and those productive advantages induced the migration that made Pittsburgh a great metropolis.

We now typically think of place-based productivity advantages as having been eroded by declining transportation costs. Indeed, Combes et al. (2010) are sufficiently confident about the irrelevance of historically important geologic features that they use them as instruments for population density, which can only be a valid procedure if geographic features are truly irrelevant to productivity today. The urban transition from manufacturing goods (which may rely on local inputs) to services (which typically do not) makes the Combes et al. (2010) assumption distinctly plausible, and suggest that unobserved place-based heterogeneity in productivity may not significantly bias agglomeration and human capital spillover estimates. ${ }^{6}$

That said, sorting on the basis of human capital remains as important as ever. Berry and Glaeser (2005) document that cities with higher skills as of 1940 or 1970 increased their skill levels more dramatically in subsequent decades. Sorting on observables into cities is relatively mild in the U.S. (Glaeser and Maré (2001)), but this is not true in Europe (Combes et al. (2008)). The problem of unobserved sorting among

\footnotetext{
${ }^{4}$ These shocks can be shocks-to-people, such as the Moving to Opportunity Experiment (MTO) (see Katz et al. (2001) and Chetty et al. (2015)) that moved poorer people to richer neighborhoods, or shocks-to-place, such as the opening of a new subway stop.

${ }^{5}$ Unobserved heterogeneity across people across people reflects the sorting of people into places based on ability levels. Unobserved heterogeneity across places reflects the tendency of people to move into areas that have exogenously higher productivity.

${ }^{6}$ However, local productivity advantages stemming from public policies may remain, as discussed by Holmes (1998).
} 
people is likely to be particularly severe when estimating human capital spillovers-in that case, the independent variable is the extent of sorting on observable skills, and it seems implausible that sorting on unobservable skills would follow the same pattern.

Identification of agglomeration or human capital externalities typically comes in two ways: shocks to people or shocks to places. The "shocks to people" approach involves looking at a sample of people who change locations for exogenous reasons. The "shocks to places" approach involves examining the impact of exogenous changes to a particular locale.

What will big data do to the estimation of agglomeration economies and human capital spillovers? Better measures of income and output will make it possible to examine things at much finer levels of spatial and temporal aggregation. Finer geographic details makes it much easier to imagine estimating the impacts of fine-grained physical geography. When agglomeration work is done at a high level of aggregation, as in Ciccone and Hall (1996), the role of street level physical space is almost imperceptible, but when agglomeration is studied in more detail, as in Arzaghi and Henderson (2008), the streetscape's role becomes more obvious.

In a sense, the geographic detail offered by big data reduces measurement error but makes sorting even more problematic. The county level employment density of 1,000 workers per square kilometer-which is higher than $95 \%$ of U.S. zip codes - tells us next to nothing about the actual density and physical structure of the work environment. If the workers are spread evenly, then there are about four workers per acre, which would suggest relatively low density suburban work environments. Conversely, if the workers are crammed together in a dense urban core, then they could be in skyscrapers.

County-level data is an extremely imprecise measure of the density experienced by the average worker, but finer detail can also be misleading because of sorting. We can look at geographic detail at a finer level even without big data sources and see the promise and pitfalls of disaggregation. Figure 1 shows the relationship between payroll per employee and employment density across 68 New York City zip codes. County business patterns zip code data on New York City is incomplete, partially because zip codes can include only one or two employers. The estimated elasticity is .30 (standard error of .027), which is over five times the estimated elasticity found using national data.

Since zip codes are much smaller than counties, zip code density really does tell us about the physical environment. For example, zip code 10171 — which has the highest earnings in Figure 1 (over $\$ 450,000$ per worker) — is one square and extremely dense block of midtown Manhattan. Zip code 10039—which is the least employment dense zip code in Figure 1-is a far less tall swath of northern Harlem.

However, while zip code-level analysis prima facie suggests a stronger density-productivity relationship than county-level estimates suggest, sorting within cities is likely to be far more extreme than sorting across cities. (No one could possibly think that the workers employed in service industries in the outer boroughs 


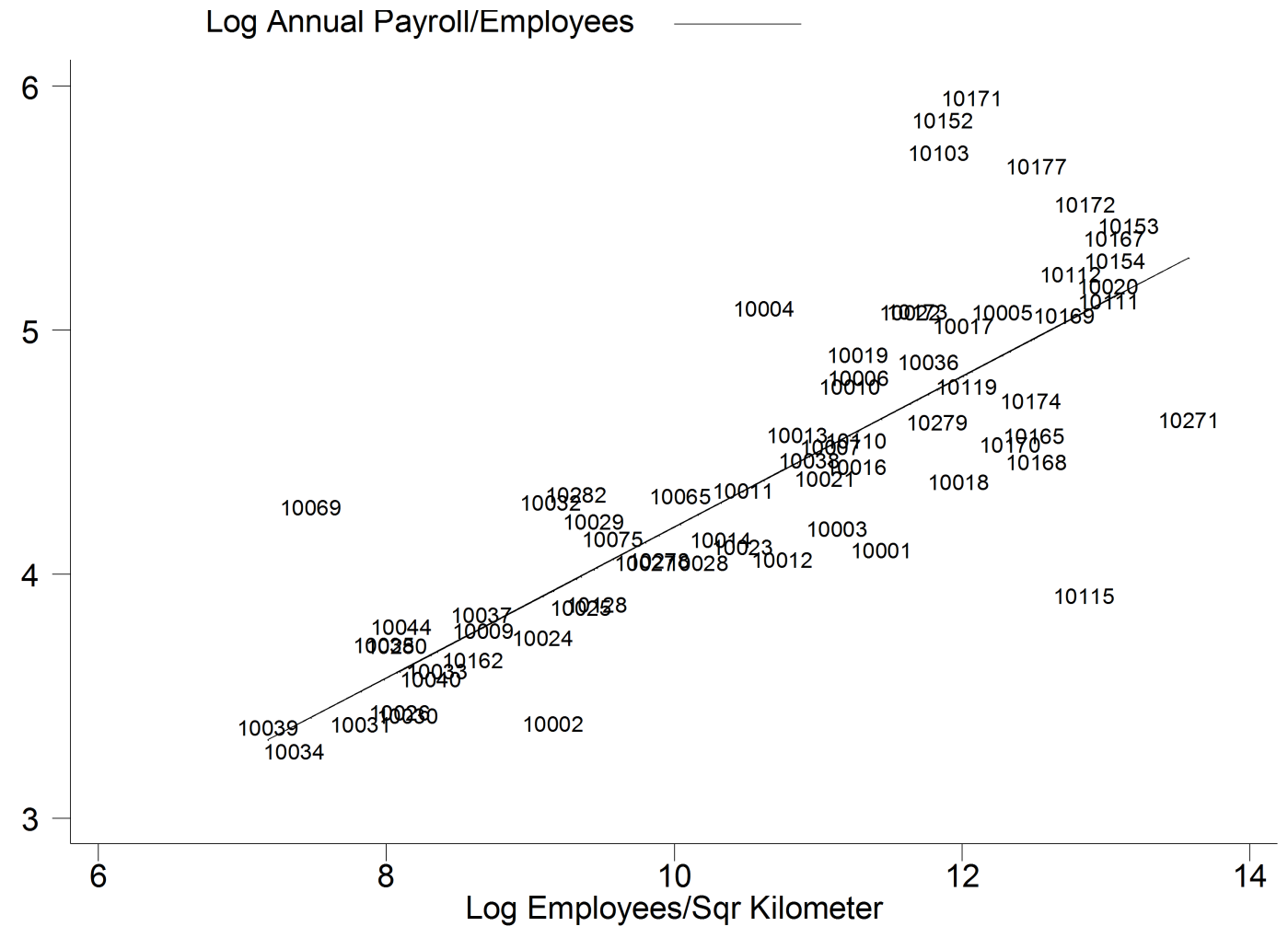

Figure 1: Per Capita Payroll and Density Across New York City Zip Codes

Data on employment and annual payroll is from County Business Patterns (2013). Data on land areas is from the 2010 Census. 
of New York are likely to have the same qualifications as workers on Park Avenue!) Moreover, spatial equilibrium models following Rosen (1979) and Roback (1982) accept spatial differences in wages that are offset by spatial differences in amenities and housing costs. Workers in Manhattan all face the same menu of housing costs and amenities. Firms may be more productive in some areas than others, but the logic of equilibrium models suggests that locational advantages in productivity within a city should be paid for through higher real estate costs, not higher wages. While we cannot know with certainty, we suspect that using finer and finer data in this case may make identification problems worse, rather than better, because increased sorting across space biases the results much more than improved measurement unbiases them.

Fine geographic and temporal detail becomes more valuable when it is merged with "shocks to places," i.e., plausibly exogenous variation varying over both time and space. ${ }^{7}$ New infrastructure, such as highways (Baum-Snow (2007)), provide one possible source of exogenous variation. Spatially delineated public policies, such as empowerment zones (Busso and Kline (2008)), provide another. If a highway or public policy is unexpected, and if there exist plausible control groups, then high-resolution data can enable researchers to plausibly estimate causal impacts by comparing areas that are close to the new infrastructure to areas that are far away. Infrastructure's impact is likely to decay continuously, but some public policies create sharp spatial breaks (as in Black (1999)). Spatial breaks make for an ideal experiment, because it is possible to compare workers literally across the street from each other. When using infrastructure changes for identification, fine data becomes extremely important: the analysis requires data fine enough to compare businesses that truly close to the change with similar businesses that are further away. 8,9

An alternative tool is the "shocks to people" approach that examines the changes in an individual's productivity when that individual is relocated from one environment to another. Again, here big data offers opportunities_-but only when it is paired with a plausible source of random variation.

Perhaps, the most famous example of a "shocks to people" experiment is the MTO (again, see Katz et al. (2001) and Chetty et al. (2015)). In this experiment, poorer households were randomly allocated vouchers that enabled and incentivized them to move to lower poverty areas. While some of the earlier analyses of MTO found minimal effects, Chetty et al. (2015) found that children who were moved early enough through MTO experienced clear improvements in earnings. Big data from the IRS was critical to the Chetty et al. (2015) study, because access to IRS records meant that all of the study's participants could be followed years

\footnotetext{
${ }^{7}$ If there is exogenous variation that differs only across space (e.g., natural aspects of geography), then sorting remains unabated.

${ }^{8}$ The value of temporal granularity is more debatable. If a change really will have immediate impacts, such as those created by an electricity outage, then big data's precision seems valuable. In the more standard case, where the time of response to shocks is uncertain, then ultra-high frequency data is likely to be less valuable. In all cases, it is better if the original inhabitants of the shocked geographic area can be followed, rather than just the current residents, since there will inevitably be some sorting ex post.

${ }^{9}$ The preceding examples show cases in which big data might improve existing estimates where there are shocks to places, but the shocks do not specifically estimate the impact of agglomeration economies or human capital spillovers unless further assumptions are added to the model. For example: A structural model can be written where agglomeration economies are created by a distance weighted measure of nearby economic activity. If distance is measured by time and cost of travel, then a shock to transport infrastructure represents a shock to agglomeration. The new infrastructure then presents exogenous variation in the amount of nearby activity and it can be used to estimate the size of agglomeration economies.
} 
after the experiment took place.

Because of unobservable sorting, estimates of agglomeration economies or human capital spillovers require experiments - big data alone is not enough. That said, big data can supplement and improve estimates from existing studies, as illustrated by the work of Chetty et al. (2015). Big data may also make it possible to estimate treatment effects of smaller-scale interventions that would be missed with classical data sources. ${ }^{10}$ There are small, natural shocks to cities every day. Big data may make it easier to use those shocks to better understand urban productivity.

\section{How does the physical city interact with social outcomes?}

While economists are particularly focused on productivity, urbanists more generally are at least as interested in social outcomes. Newman (1972) hypothesized that urban design could influence the level of crime by creating "defensible space." Architects have long argued that good buildings bring happiness, and that physical space helps shape social relations. Few people would doubt that transportation infrastructure has at least some impact on travel times and potentially on public health (Currie and Walker (2011)).

Much of urban economics has been relatively detached from many physical aspects of the city, such as architecture and streetscapes. The large literature on agglomeration economics typically relates per capita productivity or wages with some measure of economic density, such as the number of employees in the metropolitan area. The literature on housing price hedonics typically does control for measured features of housing units (e.g., numbers of bathrooms and square footage), but hedonic estimates rarely measure the appearance of the outside neighborhood or even the quality of the interior space.

The lack of connection between urban social science and the physical city is in part driven by a lack of data on the physical attributes of urban space. New big data tools make it increasingly possible both to measure the physical city and to measure outcomes that may be influenced by urban space.

Big data provides new opportunities to measure city characteristics at fine scales: At this point, the physical geography of most American cities is online and accessible to social scientists. As we describe Section 3, street-level imagery data from Google Street View can be used to measure the physical city. City maps tell us transport modes and street grids. Mapping platforms and applications provide high-frequency measures of traffic.

Big data is also providing us with a far wider range of potential outcome variables to study. Social network maps can be derived from Facebook and LinkedIn. In principle, the GPS components of smartphones enable urban mobility to be tracked on a truly fine geographic scale. In many cases, privacy concerns limit the full

\footnotetext{
${ }^{10}$ For example, credit card sales data available store-by-store, would make it easier to estimate the business impact of pedestrianizing a street or opening a new bus stop.
} 
use of the data - but new privacy technologies may make it possible to use fine data for research without significant loss of individual privacy (see, e.g., Dwork and Roth (2013)).

We also have a large amount of information on health, crime, and education outcomes. Researchers have used medical records for years, but new electronic medical record systems lead to data that is more detailed, robust, and machine-readable (see, e.g., Kho et al. (forthcoming)). Partnering with police forces allows access to daily reported crime data (Braga and Bond (2008)). Since the pioneering work of John Kain in the 1990s, researchers have been using administrative test records to assess educational interventions (Glaeser et al. (2004)).

How can newly available data help us better assess the social impact of the physical city? For an illustration, we consider the question of why mortality is now lower in many big cities such as New York. One potential explanation is lower car use, which may mean both more exercise and less risk of motor vehicle deaths.

In principle, GPS data can get us better measures of just how much walking and driving is being done by urbanites of all ages. While we have some measures of driving from the National Personal Transportation Survey, these data are based on small samples. GPS datasets can become huge and enable researchers to measure the mobility behavior of wider range of people; in principle, mobility data can also be linked with medical records to look for cross-sectional correlations.

Unfortunately, the preceding exercise again highlights that big data on its own establishes only correlationnot causality. Even if the data show that urbanites walk more and that people who walk more are healthier, we cannot interpret this as meaning that walking causes health generally or the healthy of urbanites in particular. We would need some alternative source of variation.

In order to estimate the treatment effect of walking, we would need some unanticipated shock that increases the returns to walking relative to driving. Pedestrianization of nearby roads, for example (which has been the policy of many European cities) could be such a shock. Increases in parking costs for public spaces might provide another option.

A second major social science question is the link between community cohesion and public safety. Sampson, Sampson et al. (1997) pioneered this question by using images of community connection that they hand-collected. In principle, crowdsourced community images could provide a far cheaper source of measurement; these measures can be readily linked with neighborhood-specific crime data. But even with perfect data on community connection and perfect data on crime, the correlation does not prove a causal link. Again, there needs to be some sort of a shock to connection to establish causality. ${ }^{11}$

\footnotetext{
${ }^{11}$ In this case, perhaps the closing or opening of a church or community center might provide exogenous variation. A physical reconfiguration of the neighborhood provides another possible route to causal inference.
} 


\section{How much do people value urban amenities?}

When policy-makers decide on urban investments, from infrastructure to public safety, they are implicitly or explicitly considering social costs and benefits. One of the roles of urban social science is to provide estimates of the value that consumers place on urban amenities. Big data and new survey measures provide tools for better measuring the value that consumers place on urban attributes.

There are two large strands of literature on assessing the benefits of urban amenities. Hedonic housing price models compare the prices for housing units that vary in amenities, such as safety or good views; the difference in price provides an estimate of consumers' willingness to pay for the amenity. Contingent valuation, by contrast, uses surveys—essentially asking people about their willingness to pay.

Hedonic price models make the most sense for valuing amenitues that are spatially delineated. If crime is localized to a neighborhood, then a hedonic model can (under ideal circumstances) infer a willingness to pay for lack of crime. Hedonic estimates will not be able to determine the benefit that urbanites receive from a large urban park if they do not live near that park. While we accept most of the shortcomings to contingent valuation stressed by the literature (see, e.g., Hausman (2012)), we believe that there is no alternative for evaluating spatially diffused benefits. Section 4 suggests approaches for improving the survey techniques for contingent valuation in cities. Here, we discuss the interplay between big data and housing price hedonics.

There are two classic problems that trouble housing price hedonics: heterogeneous valuations and omitted locational variables. The heterogeneous valuation problem is that consumers value amenities differently, and a hedonic price at best only estimates the willingness to pay for the marginal consumer (see, e.g., Epple (1987)). Meanwhile, the omitted locational variables problem is that every house and neighborhood is associated with a vast vector of attributes - and many of these attributes are unmeasured. The estimated value of measured attributes will be biased if those attributes are correlated with unobserved variation.

Black (1999) provides a particularly clean example of an approach that seems to solve most of the omitted variables problem, but cannot do much about the heterogeneous valuation problem. Massachusetts' towns are separated into attendance districts, which represent discrete geographic boundaries that determine where children go to lower and middle school. Black (1999) compares houses that are literally across the street from one another, but that are in different attendance districts. Since everything else about government is identical, the neighborhood is the same and the housing attributes are also quite similar, it seems quite plausible that Black (1999) estimates a willingness to pay for lower and middle schools with better test scores. Notably, however, Black (1999) can do nothing to tell us how his estimates differ from the willingnesses to pay of parents who were not on the margin between the two attendance districts.

Clean hedonic estimates can also be obtained from New York City condominium data, which Glaeser et al. (2005b) use to estimate the value of a city view. In this case, the regressions include building-fixed effects and compare identical apartments on different floors. The roughly $20 \%$ premium to being in a high floor 
seems like a reasonable estimate of the willingness to pay for a view, although it is possible that this estimate is compromised slightly by the presence of ritzier neighbors on higher floors.

How can big data improve housing price hedonics? The first contribution is the proliferation of dense data sets with information on home sales by address. Such data sets have always been available. Black (1999), for example, used information from Banker and Tradesman on home sales in Massachusetts. But since house sales are public information, data sets on sale prices are becoming more common and less expensive. Eventually, they may make research that relies on self-reported housing values from the Census or American Housing Survey obsolete. Unfortunately, sales data may include only a very limited set of housing characteristics, and sales data rarely contain detailed information about the physical nature of the housing stock. One approach is to look at repeat sales and assume that the physical characteristics of a house have remained constant over time- but this assumption is often hard to accept. ${ }^{12}$ Alternatively, sales data must be combined with alternative sources of information about housing characteristics - a natural big data frontier. ${ }^{13}$

As many physical amenities are interior, big data aggregators are going to have to work harder to get estimates of interior space. One natural source for interior information is the floor plans and images connected to addresses by web sites like Zillow and Craigslist. If interior images can be downloaded at scale, then they can be linked to sales prices, just as external images can (see Section 3). While even high-resolution images may not allow us to control for unit quality perfectly, they certainly include far more information about unit characteristics than current hedonic analyses do.

Beyond the physical landscape, big data provides novel information on the test scores of local schools or the quality of local restaurants. Yelp, for example, provides block-by-block data on the popularity of local services. While service quality will not be exogenous, it can be part of a hedonic system that measures willingness to pay. Social patterns are also more observable from Twitter locales as well, and this lets researchers estimate which areas are popular on, say, weekend nights.

We must note, however, that while big data can provide stunningly precise pictures of life within a particular neighborhood, it can never fully satisfy the omitted variables problem. When neighborhood attributes are endogenous, controlling for them becomes problematic_-and researchers would need even more sources of exogenous variation.

Big data means better price data and a far larger vector of potential explanatory variables. It does not mean that there are clear sources of exogenous variation in local attributes. Moreover, housing price dynamics are murky. It may take minutes or months for a shock to percolate into housing values. Consequently, highfrequency price or rent data is unlikely to provide clean identification of the impact of shocks. Big data will

\footnotetext{
${ }^{12}$ For example, Autor et al. (2014) look at the changes in prices after rent control, but they explicitly accept that these changes will include the effects of unmeasured quality upgrading.

${ }^{13}$ Gregoir et al. (2012) provide a nice example of a particularly large data set on rents and housing data, but their data is unusual. At present, observing the physical characteristics of a house typically means relying on a traditional government survey.
} 
enable us to run hedonic price regressions with more explanatory variables, but it will not on its own enable us to run better-identified regressions.

\section{How can public policy improve the quality of physical space?}

Beyond its value for academic analysis, big data provides opportunities to improve the quality of public services. In this context, causality sometimes remains important—but at other times, simply being able to predict outcomes is valuable on its own.

Perhaps the most natural use of big data in city governance is for management. The New York City Police, for example, Department credits the highly local measurement of crime as being a major part of making New York safe. Knowing exact locations of each crime enabled police to target resources and find criminals. Data made it easier to hold precinct chiefs accountable.

The data-driven approach to policing works for other public services, as well. The Street Bump mobile app, for example, streams data about potholes from people's cars to Boston's street repairers; the data comes from jolts to the citizens' smart phones. ${ }^{14}$ Similarly, big data makes it easier to have systems for citizen complaints that enable the citizens and public monitors to monitor progress. For example, Massachusetts's Commonwealth Connect app, built off of Boston's Citizens Connect app, enables individuals “to report [urban] issues to the appropriate local municipality, even when the user doesn't know which department or municipality should respond". ${ }^{15}$

As we discuss in Section 5, big data also makes it easier to target city services like restaurant inspections. If Yelp complaints about the sanitary conditions in a restaurant are particularly high, then this provides information that can help to target inspectors-a limited resource. Likewise Yelp's rating of particular city offices provides an alternative source of information that may be useful to urban management.

Yet the opportunities that are created by big data can, in principle, collide against the government institutions (or strong public sector unions) that make it difficult to change work rules or institute data-based incentives. Thus, perhaps the best opportunities for using big data in city management arise in settings where the interests of public workers are not threatened by the data. Technologies that make it easier for teachers to target their teaching are much easier to implement than technologies that make it easier to evaluate teachers. Labor-saving big data tools, such as automated appraisal methods, are easier to contemplate when the workers are outside contractors, rather than unionized city officials.

\footnotetext{
${ }^{14}$ See http: //www. streetbump.org/.

${ }^{15}$ See http: //www. cityofboston.gov/doit/apps/commonwealthconnect. asp, and also Weiss (2015).
} 


\section{Measuring the Streetscape}

While many of the core urban questions require exogenous variation, there are cases in which measurement itself can be of great value. In this case, big data can bring advances even without natural or planned experiments. In this section, we detail how applying computer vision algorithms to Google Street View data (or other image corpora) can be used (1) to measure the physical characteristics of a neighborhood and (2) to estimate neighborhood income.

In the past decade, Google Street View has extensively photographed the built environment in more than 100 countries. Almost all American cities have been documented in high-definition; the resulting images can be classified using computer vision algorithms. The basic approach is to have some form of training data, which includes Global Positioning System (GPS)-coded attributes of interest (such as housing prices, income, or ratings of urban upkeep). The computer vision algorithm then learns to predict the target attribute from high-dimensional moments of the arrangements of pixels in the imagery. Since training on high-dimensional features can easily result in over-fitting, the predictive model is tested on a second sample. If the model's fit on the test sample seems good, then the model can be used to generate estimates of the focal attribute for settings in which the underlying attribute data is not available.

Naik et al. (2014) provide one example of how Street View can be used to measure the physical attributes of a neighborhood. They begin with crowdsourced ratings of perceived safety for 4,109 images (see also Salesses et al. (2013)). Human perceptions of safety are then taken as the focal attribute, and computer vision algorithms are used to scale the safety assessment to a sample of 1,000,000 images across 21 cities. Using the Naik et al. (2014) measurements, we have now examined patterns of change in predicted perceived safety, and documented that areas that are denser or better educated saw the largest improvements in perceived safety at the neighborhood level (Naik et al. (2015)).

In this section, we consider two distinct but related questions. First: Can Street View imagery data be used to predict income? Second: Can Street View data improve the quality and fit of hedonic regressions? The first question is most relevant in the developing countries, where often we have large image corpora, but no reliable large-sample income data. The second question is likely to be more relevant in the developed world, where we have price data but typically have not used visual images of the streetscape as explanatory variables. Predicting prices with streetscape imagery may also have public policy value as a tool in property value appraisal in places (both developed and developing) where governments rely on property taxes.

If images are available for an entire city, then we can use a computer vision model trained on a small sample of income data to produce a citywide map of wealth and poverty, as well as measures of income segregation. If we have images at different point in time, we can then test how individual interventions changed the distribution of wealth. 

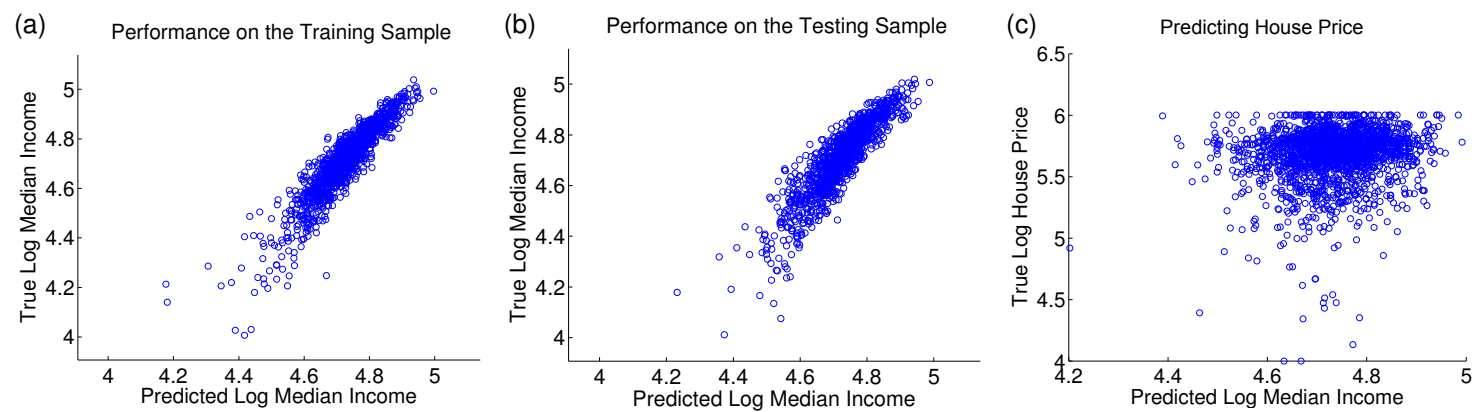

Figure 2: Predicting Income and Housing Price from Street View Images

Median income for New York City is obtained from the 2006-2010 American Community Survey.

\section{Predicting Income and Housing Prices with Pixels}

As a proof of concept, here we demonstrate that we can predict the median income of residents in New York City from Street View images using a computer vision model. We also show that the computer vision model trained to predict median incomes from images from New York City is able to predict the median income of images from Boston with almost the same accuracy as in New York. Finally, we link predicted income with housing prices to show the potential use of this technology in hedonic housing price regressions.

We queried the Google Street View Image API to obtain cutouts from 3600 panorama images captured by the Street View vehicles between 2007 and 2014. The cutouts were obtained by specifying locations (using latitude, longitude values) and camera viewpoints (using the heading and pitch of the camera relative to the Street View vehicle). We randomly selected latitudes and longitudes from a uniform grid overlaid on city boundaries. ${ }^{16}$ We set the heading to 900 and pitch to 100 for all images. For this study, we set the sampling factor to 40 images per square mile and obtained 12,200 images from New York City and 3,608 images from Boston.

We linked our image data to median family income data at the census block group level using the American Community Survey (ACS) data, which aggregates the samples collected between 2006 and 2010. The images from New York City cover 2,439 block groups at a resolution of 10 images per block group, while the images from Boston cover 459 block groups at a resolution of 15 images per block group. There are a few census block groups with reported incomes clipped at $\$ 1,000,000$. We clipped the incomes at $\$ 118,550$, which is two standard deviations above the mean of median incomes across the block groups. Finally, we coverted the reported incomes to logarithmic scale.

To predict median income from Street View images, we followed Naik et al. (2014), who predict the perception of safety from Street View images. We began with a modified version of the Geometric Layout algorithm (Hoiem et al. (2008)) to assign pixel-wise semantic labels. We assigned pixels to four geometric

\footnotetext{
${ }^{16}$ We obtained this grid by selecting centroids of an unstructured simplex mesh computed over a polygon describing city boundaries (Persson and Strang (2004)).
} 
classes: "Ground," "Buildings," "Trees," and "Sky." Next, we extracted three image features from the pixels that belong to the four geometric classes separately. We extracted 512 dimensional Texton maps (Malik et al. (2001)) from each geometric class. ${ }^{17}$ Next, we extracted the GIST feature descriptors, which represent the spatial layout properties of a scene (Oliva and Torralba (2001)), for each of the geometric classes. After that, we extracted color information from images with joint histograms in CIE $L \cdot a \cdot b$ color space. ${ }^{18}$ Finally, we merged our three feature sets-textons, GIST, and color histograms-to obtain a 7,480-dimensional representation of each image.

After feature extraction, we used $v$-Support Vector Regression ( $v$-SVR) (Schölkopf et al. (2000)) to predict income from Street View images. Given a set of training images with feature vectors $x$ and income $y, v$ SVR with a linear kernel generates a weight vector $w$ and a bias term $b$ under a set of constraints. The two variables $(w$ and $b)$ are used to predict the income for a new image with feature vector $x^{\prime}$ by evaluating

$$
y^{\prime}=w \cdot x^{\prime}+b
$$

For training, we used the libsvm (Chang and Lin (2002)) implementation of $v$-SVR. ${ }^{19}$

We randomly selected images from half of the block groups from New York City to use as the training set. We then trained a $v$-SVR model, and used this model to predict the income of images from the "test set" comprised of block groups excluded from the training set. We averaged the predicted incomes of images from these census block groups to obtain an estimate for their median incomes. The results from this exercise are shown in Figure 2(a) and Table 1.

The first column in Table 1 shows the correlation between the predicted income measure and the actual income measure for the training sample. For comparison purposes, we have also included percent white and the share of the adult population that is college-educated. Across our 1220 observations, the $R^{2}$ is 0.85 , indicating that the fit is quite good. Notably, almost all of the fit is coming from the visually predicted income measure, which has a $t$-statistic of 70. By contrast, the $t$-statistic for college share is under 5 . Without, the race and education variables the $R^{2}$ would be 0.77 . Without the predicted income measure, the $R^{2}$ for education and race would be 0.25 .

But the results on the training sample are relatively uninformative. In principle, the image data is sufficiently rich that we could massively over-fit the data-essentially we would be using a vector of explanatory variables with 1220 elements (or more) to explain a data set with 1220 observations. The real test of the technology lies in regression (2) of Table 1, in which we examine the link between predicted income and reported income in the test sample. Somewhat remarkably, the results are virtually unchanged. The $R^{2}$ of the regression is .81 . The $t$-statistic on predicted income is 62 . Images can predict income at the block group

\footnotetext{
${ }^{17}$ Texton maps encode the textures of objects such as walls, foliage, and streets.

${ }^{18}$ The 3D histograms had 4, 14, and 14 bins for $L, a$, and $b$ channels, respectively.

${ }^{19}$ We set the slack variable $(C)$ to 0.01 .
} 
level far better than race or education dos.

Without the race and education variables, the $R^{2}$ would .77 , meaning that images capture $77 \%$ of the variation in this sample. To visually demonstrate the fit, Figure 1(b) shows a scatter plot of income and predicted income in the testing sample. While the fit is not perfect, the correlation is remarkably strong.

In regression (3), we look at the connection between income and predicted income in Boston. We continue to use the predictive model drived from the New York training data-there is no Boston-specific fitting of income to pixels. We find an $R^{2}$ of 0.86 ; the $t$-statistic on predicted income is 46 . Without other controls, the $R^{2}$ would be .71 . Our computer vision model works well even for extrapolation to cities other than New York. $^{20,21}$

\section{Hedonic Pricing}

We now turn to our next exercise: linking images to prices (Table 2). In this case, we are interested in the extent to which physical attribute can add predictive power to models in which we are trying to predict housing prices. In some cases, we may just be interested in expanding predictive power-perhaps if the government is trying to improve an automated appraisal process for property tax purposes. In other cases, we may actually want to know which physical attributes explain differences in housing values. Street View imagery may be useful in both settings. For example, computer vision technology is beginning to enable use to identify particular street level attributes, such as potholes. In principle, these attributes can be added as regressors in a hedonic price model. At present, however, we focus on the simpler task of just predicting prices with pixels.

We continue to use predicted income as our key dependent variable. ${ }^{22}$ In essence, the regression is asking whether neighborhood physical attributes that attract rich people also increase housing prices.

Regression (1) shows that predicted income does have significant explanatory power for prices in the training sample. The coefficient of 4.4 means that as predicted income increases by 1 log point, predicted prices increase by $4.4 \log$ points. The $t$-statistic is approximately 7 .

Regression (2) repeats the exercise of regression (1), but using the testing sample. The coefficient in this sample rises slightly-to 4.8 -and the $t$-statistic is now over 7.5. One possible explanation for the slight discrepancy between the samples is that over-fitting within the training sample actually caused the predictive

\footnotetext{
${ }^{20}$ This does not prove that the model will work everywhere in the U.S., much less in the developing world. Boston and New York are reasonably similar places, with comparable income levels and similar building stocks. More recently built metropolises like Houston are likely to have very different patterns linking images and income. The patterns in the developing world will be even more different. Our results here prove that pixels can predict income for block groups in New York. While suggestive, our analysis here does not yet prove that pixels can predict income in Johannesburg or Bangladesh.

${ }^{21}$ Also, we note that our analysis was done using block group data, rather than individual address data. We suspect the income fit will be worse when we move to the address level, since aggregating to the block group level essentially averages over heterogeneity.

${ }^{22}$ We could have directly predicted housing values from the images, but using predicted income slightly reduces the chance of over-fitting and predicting housing values with idiosyncratic features that happen to be linked to housing prices in this data.
} 


\begin{tabular}{lccc}
\hline \multirow{2}{*}{ VARIABLES } & $\begin{array}{c}(1) \\
\text { True Log } \\
\text { Income } \\
\text { New York } \\
\text { (training) }\end{array}$ & $\begin{array}{c}(2) \\
\text { True Log } \\
\text { Income } \\
\text { New York } \\
\text { (testing) }\end{array}$ & $\begin{array}{c}(3) \\
\text { True Log } \\
\text { Income } \\
\text { Boston } \\
\text { (testing) }\end{array}$ \\
\hline Predicted Income & $1.328^{* * *}$ & $1.357^{* * *}$ & $1.639 * * *$ \\
& $(0.019)$ & $(0.022)$ & $(0.036)$ \\
Share White & 0.003 & 0.001 & $0.033^{* *}$ \\
Share College-Educated & $0.046^{* * *}$ & $0.076^{* * *}$ & $(0.015)$ \\
& $(0.011)$ & $(0.013)$ & $(0.016)$ \\
Observations & & & \\
R-squared & 1,220 & 1,219 & 459 \\
\hline
\end{tabular}

Table 1: Regressions of Income on Predicted Income and Socioeconomic Variables

Regressions (1) and (2) control for borough fixed effects. Socioeconomic variables are obtained from the 2006-2010 American Community Survey. Standard errors are in parentheses. Regressions are estimated with a constant that is not reported. $* * *=p<0.01, * *=p<0.05, *=p<0.1$

\begin{tabular}{lccccc}
\hline \multirow{2}{*}{ VARIABLES } & $(1)$ & $(2)$ & $(3)$ & $(4)$ & $(5)$ \\
& $\begin{array}{c}\text { True Log } \\
\text { House Price } \\
\text { New York } \\
\text { (training) }\end{array}$ & $\begin{array}{c}\text { True Log } \\
\text { House Price } \\
\text { New York } \\
\text { (testing) }\end{array}$ & $\begin{array}{c}\text { True Log } \\
\text { House Price } \\
\text { New York } \\
\text { (training) }\end{array}$ & $\begin{array}{c}\text { True Log } \\
\text { House Price } \\
\text { Boston } \\
\text { (testing) }\end{array}$ & $\begin{array}{c}\text { True Log } \\
\text { House Price } \\
\text { Boston } \\
\text { (testing) }\end{array}$ \\
\hline Income Residual & & & $3.982^{* * *}$ & & $3.601 * * *$ \\
Predicted Income & $4.372^{* * *}$ & $4.833^{* * *}$ & $3.412^{* * *}$ & $7.722^{* * *}$ & $5.420^{* * *}$ \\
& $(0.631)$ & $(0.643)$ & $(0.701)$ & $(0.709)$ & $(0.909)$ \\
Share White & $0.778^{* * *}$ & $0.492^{* *}$ & $0.486 * *$ & 0.204 & 0.085 \\
Share College-Educated & $(0.187)$ & $(0.196)$ & $(0.194)$ & $(0.303)$ & $(0.300)$ \\
& $1.128 * * *$ & 0.459 & 0.156 & $-0.983 * * *$ & $-1.028 * * *$ \\
& $(0.369)$ & $(0.386)$ & $(0.387)$ & $(0.334)$ & $(0.329)$ \\
Observations & 1,220 & 1,219 & 1,219 & 459 & 459 \\
R-squared & 0.218 & 0.225 & 0.240 & 0.223 & 0.249 \\
\hline
\end{tabular}

Table 2: Predicting Housing Price with Income and Socioeconomic Variables

Regressions (1)-(3) control for borough fixed effects. Socioeconomic variables are obtained from the 2006-2010 American Community Survey. Standard errors are in parentheses. Regressions are estimated with a constant that is not reported. $* * *=p<0.01, * *=p<0.05, *=p<0.1$ 
model to hit idiosyncratic income features of the training sample; when applied elsewhere, the model does a slightly better job of picking up generic features of neighborhood attractiveness, which in turn do a better job of predicting prices. Figure 2(c) shows the relationship visually; while the fit is far from the overwhelming correlation shown in Figure 2(b), it remains significant.

Regression (3) shows the results controlling for the residual between the actual income and the predicted income in the testing sample. Since income is a strong predictor of housing price, and predicted income is not exactly equal to the actual income, the coefficient for the residual is fairly large - in fact, it is larger than the coefficient for the predicted income.

Regression (4) shows the results for Boston when we do not control for actual income. As in the case of New York, predicted income has significant explanatory power for housing price. In fact, the coefficient for predicted income is 7.7, which is much higher than the coefficient for predicted income in New York. We also note that the coefficient for the share of college-educated adults (somewhat peculiarly) is negative and significant.

Regression (5) shows Boston results controlling for the residual between the actual income and the predicted income. As we found in regression (3), the coefficient for the residual is fairly large (3.6), although smaller than the coefficient for predicted income (5.4).

Thus, we see that Google Street View can predict income in New York and Boston, and predicted income helps us predict housing prices in our sample. This does not mean that we can predict income well in the developing world, but it does provide some hope that Google Street View and similar predicts will enable us to better understand patterns of wealth and poverty worldwide.

\section{Survey Methods}

In this section, we turn to the role that survey methods can play in evaluating public investments in urban space. The basic policy problem is to evaluate the benefits of an investment (such as a park or a new subway line) or a regulation (such as a height restriction). We assume that the amenity has significant "passive use" or "existence" value (Krutilla, 1967) or that there are social and political prohibitions against charging for use, as there are in most urban public spaces.

Environmental economists, starting with Ciriacy-Wantrup (1963) and Davis (1963), were motivated by similar conditions to use "contingent valuation" methods to evaluate environmental amenities, such as access to the Maine woods. Contingent Valuation techniques essentially ask respondents about willingness to pay for environmental amenities. The problem of assessing how much Chicagoans value an extra park or New Yorkers value an extra historic preservation district is intrinsically similar to the problem of assessing how much Americans value species preservation or clean beaches. If contingent valuation works in one setting, 
then it should work in both.

However, it is far from clear that contingent valuation works in the environmental domain. Diamond and Hausman (1994) and Hausman (2012) have written compellingly on the empirical shortcomings of contingent valuation surveys. Respondents often provide extremely high valuations for environmental amenities that seem disconnected with the size of the environmental benefit. Desvousges et al. (1993) found that the willingness to pay to protect 2,000 birds is essentially identical to the willingness to pay to protect 200,000 birds. Kahneman and Knetsch (1992) documented an "embedding effect," whereby the willingness to pay for a good "depends on whether it is evaluated on it own or as part of a more inclusive category."

Pro-contingent valuation economists have fought back by providing models in which contingent valuation surveys are incentive compatible, assuming that preferences are classically instrumental and rationality is robust (Carson and Groves (2007)). As long as there is some probability that a given survey will determine policy, then a well-posed question that pits costs against benefits should induce a fully rational respondent to accurately reveal preferences because there is some chance that this respondent's views will determine policy. But given the empirical problems associated with contingent valuation, it is tempting to see contingent valuation as another setting in which the predictions of hyper-rationality fail.

There are two problems with contingent valuation of environmental amenities that are potentially less pernicious in urban settings: non-familiarity and non-instrumental preferences. The non-familiarity problem occurs when surveys ask questions about topics that are quite far from the daily experience of most respondents. Asking most Americans about oil drilling in Alaska, for example, requires them to speculate about a topic that is extremely far from their daily life; for such a topic, given that most agents have neither the tools nor the incentives to investigate fully, why should we expect sensible answers? Even more importantly, 39\% of Americans identify themselves as environmentalists (Pew Research Center (2014)). The identity framework of Akerlof and Kranton (2000) suggests that anyone whose self-image is tied to environmentalism could easily have a non-instrumental reason for giving aggressively pro-environment responses to a surveyor: such responses "prove" environmentalism, either to the individual him or herself, or to the surveyor. ${ }^{23}$

In this section, we first make the case that contingent valuation has a place in urban policymaking if it can be done with any accuracy. We then discuss responses to the problems of non-familiarity and non-instrumental responses. Finally, we illustrate how contingent valuation might be applied in three settings: evaluating a new park in Chicago's Northerly Island, establishing a preservation district in Bedford, Brooklyn, and imposing height limitations on buildings that abut Boston's Rose Kennedy Greenway.

\footnotetext{
${ }^{23}$ This argument is akin to the "warm glow" that is warned against in the NOAA Report on Contingent Valuation (Arrow et al. (1993)).
} 


\section{Why contingent valuation in the city?}

Given the problems that Hausman (2012) and others find with contingent valuation, it is tempting to abandon such survey methods altogether. But in cities, decisions often need to be made about policies that cannot be evaluated using non-survey techniques. Moreover, unlike in environmental or other purely public good domains, in cities the alternative to contingent valuation surveys is not careful, technocratic evaluation, but the messy decision-making of urban interest group politics.

The economist's first battle in urban policy is to push for any form of cost-benefit analysis—and that battle is usually lost. Contingent Valuation analysis seems significant because it has the potential to make costbenefit analysis more palatable in settings where existence value is thought to be considerable. The case for cost-benefit analysis in historic preservation, for example, seems much stronger if there is at least some mechanism for capturing the extent to which pedestrians appreciate the experience of older urban spaces.

There are settings in which hedonic values capture some or all of the social value from an amenity. The price premium paid near Central Park provides one means of assessing the value of the park. Yet the high prices on Fifth Avenue may both over- and under-estimate the true value of that vast urban green space. Environmental amenities attract the rich, and the Fifth Avenue price premium may overstate the true value of the park because it also captures the perceived value of living next to the super wealthy. If a park premium is assessed in a model with city-level fixed effects, then the econometrician cannot determine whether the rise of values near the amenity represents a pure increase in values or just a transfer in value form places far from the amenity to places near the amenity. Alternatively, the proximity premium may understate the

true value of the amenity because even residents who live far away from the park may derive a lot of value from it.

Hedonic price estimates have a role in urban policy-making, but they are also-like contingent valuationan imperfect technique. For assessing the usefulness of contingent valuation in cities, we should not ask whether the survey results look like the coherent preferences described in graduate microeconomics, but whether they provide information that is, in some way, useful for policy assessment.

In most cities, the typical decision-making process is a mixture of interest group lobbying, local legislatures, and executive authority — with little formal cost-benefit analysis of any sort. This process produces zoning, most urban parks, historic preservation and subsidies to lure large employers. Elected officials are the only safeguard of general well-being against interested parties. It is hard to see the downside of bringing some contingent valuation polling into their decision-making, as long as the flaws of the method are well understood.

A preference elicitation alternative to contingent valuation is the use of direct referenda. Direct democracy has both fans (Matsusaka (2005)) and detractors (Schrag (2004)), and we do not mean to take a stand on the use of referenda, in general. Yet we note that referenda seem to suffer from many of the problems associ- 
ated with contingent valuation surveys. Experts on referenda also that question wording can be extremely important in referenda, just as in contingent valuation surveys (LeDuc (2003)). Referenda may be slightly more incentive compatible than contingent valuation surveys, but this difference is vanishingly small in a probabilistic sense, because the odds of being the pivotal voter in a referendum are extremely close to $0 .{ }^{24}$

\section{The Problems of Contingent Valuation - and Two Proposed Solutions}

\section{An Illustrative Example}

The potential upside of using contingent valuations in the case of urban policymaking is illustrated by the case of Lexington, Kentucky, which debated subsidizing a new hundred-million dollar stadium for the University of Kentucky Bobcats, a wildly successful college basketball team (Johnson and Whitehead (2000)). Sports teams surely generate plenty of non-use value, so it may make sense to consider subsidies to sporting teams - but in this case, the stadium was not necessary to keep the team in the town, and it was not obvious that the stadium would help the team win. Johnson and Whitehead (2000) used contingent valuation methods and found that local citizens valued the new stadium at less than $\$ 5$ per year-seemingly quite relevant, given that decisionmakers were considering a vast subsidy.

The Kentucky example seems largely free of the problems of non-instrumentality and non-familiarity that bedevil many environmental contingent valuation surveys:

- Respondents were familiar with the Kentucky basketball team and were largely familiar with fancy stadiums. Americans watch a lot of sports, and even those who do not patronize sky boxes themselves have surely seen them on television. Respondents were able to draw two surely correct conclusions about the situation: A more expensive arena would not actually improve the play of their beloved basketball team. Moreover, since the Bobcats were a college team, not a professional team, there was no chance that the team would change its location if it did not get the stadium. As a result, even the most ardent Bobcats fan knew that the proposed hundred-million dollar investment would not impact the likelihood of a having the Bobcats in town.

- Meanwhile, there were many local respondents whose identities were somewhat linked to being Bobcats fans. Yet rooting for the Bobcats was not associated with supporting more luxurious seats for wealthy Bobcats patrons. Consequently, one could be a perfectly loyal Bobcat fan without being willing to support the new arena; so, there was no non-instrumental value in stating a large willingnessto-pay.

In the sequel, we discuss the generality of the non-instrumentality and non-familiarity problems, and illustrate several potential ways of addressing both problems in urban contexts.

\footnotetext{
${ }^{24}$ Caplan (2011) reminds us of the many examples in which voters are misinformed and appear downright irrational—which may be unsurprising given the unfamiliarity of most political issues and the limited incentives that voters have to gather information.
} 


\section{Issue 1 - Non-Consequential Motives in Survey Response}

Carson and Groves (2007) take the view that economists have little to say about non-consequential motives in survey response because such responses are far away from conventional economics. We respectfully disagree and certainly, there is plenty of scope for economists to test hypotheses about non-consequential preferences.

For simplicity, consider a 1-0 survey question about taking some environmental action that comes with a cost, such as paying $\$ 1,000$ per person to protect a species of owl. Assume that the net benefit to the survey respondent of the action is $b_{i}$, and the probability that the survey (or vote) will be pivoted is $\pi_{i}$. As long as $\pi_{i}>0$, and there are no other preferences bearing on the response, then the individual will give the true answer.

Yet assume that the individual has some non-consequential benefit $v_{i}$ from saying "yes" to the question, and that $v_{i}$ is independent of $\pi_{i}$. The response will be yes if and only if $v_{i}+\pi_{i} b_{i}>0$; in that case, as $\pi_{i}$ becomes small, survey responses will entirely reflect $v_{i}$ rather than $b_{i}$. If, as Carson and Groves (2007) suggest, we have nothing to say about $v_{i}$, then we can indeed do no better than take the survey as a measure of $b_{i}$ - but we $d o$ know things about non-consequential motives, self-deception and the economics of identity.

If all environmentalists receive a positive payoff from giving a pro-environment answer, then if $\pi_{i}$ is small, people who identify as environmentalists will say "yes" to any pro-environment question, regardless of cost. According to this view, the number of birds saved in Desvousges et al. (1993) do not impact the survey responses because the survey respondents are primarily answering for non-instrumental reasons, to show their fidelity to their environmentalist identities. Any non-instrumental force can lead to responses that are independent of benefit magnitude; this provides a natural explanation of the embeddedness results of Kahneman and Knetsch (1992).

\section{Issue 2 - Non-Familiarity with the Survey Topic}

In the framework of the preceding section, non-familiarity might just mean that respondents assess $b_{i}$ with abundant error. In principle, non-familiarity could just lead to noisy results. But non-familiarity could also lead to worse forms of bias. For example, if respondents recognize the limits of their knowledge about benefits, this could lead them to place even more weight on non-instrumental motives when answering. Or respondents may rely heavily upon cues embedded in the survey itself. ${ }^{25}$ In this light, the extreme sensitivity of survey results to framing is not evidence of irrationality, but rather a natural response to ignorance about the topic. Respondents are sensitive to framing because their basic knowledge is limited.

\footnotetext{
${ }^{25}$ A question's wording presumably gives some sense of that question's importance, as does the attitude of the surveyor.
} 


\section{Potential Solutions}

Surveys should be able to reduce the non-instrumental forces in responses by offering alternatives that occur within the same domain, and thus are hopefully comparable on non-instrumental grounds. Meanwhile, nonfamiliarity can be minimized by posing options that are relatively easy to understand. Sometimes, however, the two objectives are in conflict.

For example, consider an attempt to use contingent valuation to assess willingness-to-pay to clean up petroleum around a coastline. An identity-comparable alternative might be "spending money to expand research on renewable energy"; the survey can work towards environmental neutrality by highlighting the environmental benefits of both courses of action. ${ }^{26}$ Yet both options suffer from non-familiarity. Perhaps with enough pictures and discussion, the "clean coastline" can be turned into something comprehensible. But it is hard to see how ordinary Americans will ever have much of a sense of what two billion dollars in renewable energy research will accomplish—especially since experts would have trouble agreeing about such an investment. Thus, it seems reasonable to consider alternatives that run more risk of non-instrumental responses but that have the virtue of greater familiarity and comprehensibility. For example, spending on cleaning up the coastline could be compared with expanding early education for the poor. ${ }^{27}$

Non-familiarity may be less of an issue in cities since most urban investment questions are readily comprehensible to ordinary people. But contingent valuation for some urban amenities may suffer from the same identity or other non-instrumental issues as environmental surveys. ${ }^{28}$ Moreover, there are other identities that can also matter within an urban setting. There is a preservationist movement that supports the protection of older buildings, and there are urbanist identities that would be associated with more walking and public transportation and less driving; questions that trigger these particular identities seem likely to yield biased results.

As in the case of broader non-use surveys, contingent valuation methods for urban amenities should attempt to minimize the role that non-instrumental forces will play in driving answers, by matching the alternatives along identity dimensions. Moreover, they should also work to ensure as much familiarity as possible. We now consider three detailed urban examples and discuss an approach to contingent valuation that incorporates concerns about non-instrumental responses: Northerly Island in Chicago, the proposed Bedford Historic District in New York City, and proposals to build up along the Rose Kennedy Greenway in Boston.

\footnotetext{
${ }^{26}$ The NOAA Report (Arrow et al. (1993)) recommended that survey respondents be reminded of alternative uses of funds, including environmental uses, and warned of a warm glow phenomenon, when respondents feel good about giving a particular answer. Yet reminding someone that money saved can be spent on something else-which might be environmental in nature-is not at all equivalent to giving a true environmental alternative. The environmentalist identity would surely still push towards the environmental answer in the former case, but not in the latter.

${ }^{27}$ While this approach might not be as biased as weighing environmental benefits against taxes, it does introduce a second identity issue-it could well end up measuring the power of the environmentalist identity against a more general pro-poor progressive identity.

${ }^{28}$ Indeed, support for an urban park can be seen as being just as much of an environmentalist action as cleaning up a coastline.
} 


\section{Northerly Island}

Northerly Island is a current project in Chicago to repurpose the former Meigs Field airport into a park with natural habitats. Northerly Island is man-made, so it is not a return to nature. Still, the project can be seen as environmentalism both because it brings green space into the city and because it will offer a protected habitat for some wild creatures.To our knowledge, neither the decision to eliminate Meigs Field nor the decision to repurpose the space for a park have been subjected to cost-benefits analysis. ${ }^{29}$

We consider solely the question of valuing the Northerly Island park-not the decision to eliminate the airfield. The natural alternative to the park would be leasing the land to a private developer who would develop the space in some means concordant with city ordinances and regulations.

A first approach to valuing Northerly Island would be to conduct a contingent valuation survey in which Northerly Island is compared to a variety of cash outcomes. Not having the park would mean lower taxes. But since a considerable fraction of the park's costs is to be paid by the Federal government, the actual tax implications are likely to be quite modest; this comparison would almost surely lead to a strong nonconsequentialist bias in favor of the park. Evaluating spending reductions-especially when complex tax policies and Federal budgets are involved — can also have non-familiarity problems.

A more nuanced approach is to conduct a survey comparing Northerly Island to the alternative of a private lease, with different revenue levels to be paid to the government and allocated to an alternative worthy cause, such as a trust for increasing pre-school availability for disadvantaged children in Chicago. ${ }^{30}$ This approach will provide us with two competing warm glow effects: respondents' environmentalist identities will compete against their progressive identities. While the two options may both have familiarity, they will also test the relative size and power of different identity groups within Chicago, which may make interpretation more difficult.

A third approach is to give the alternative of a private lease, with different revenue levels to be paid to a trust that will also benefit the local environment. In this case, a trust for investing in Chicago's park system (and particularly, animal life) seems natural. One option might be to increase spending on the publicly funded Lincoln Park Zoo. In this case, likes are truly being compared with likes, and environmentalist identity should not shape the results. The large challenge is to make the Zoo alternative comprehensible and familiar to respondents. Some work would need to be put in to ensure that the alternative park spending delivers outcomes that make sense. The Zoo offers the option of giving a clear number of animals that could be brought to the city. It may however offer a slightly different non-instrumental payoff.

While the identity logic we have discussed suggests that the third option is least problematic on its own,

\footnotetext{
${ }^{29}$ See http://friendsofmeigs.org/resources/2012-07-06_Friends_of_Meigs_Field_Comments_ for_USACE_plan_for_CGX.pdf.

${ }^{30}$ Chicago currently has tuition-based pre-school, so that the program could essentially eliminate the pre-school tuition for a fixed number of students — and that should be readily comprehensible by most survey respondents.
} 
perhaps the best approach is to use all three surveys and compare the responses. The degree of variation in responses indicates the extent to which identity is important for the question at issue. If identity does turn out to be strongly relevant, the third approach might be taken as providing the best single answer-but the heterogeneity in responses provides us with a sense of how much we can trust the answers.

\section{Shadows on the Rose Kennedy Greenway}

For almost fifty years, Boston had an elevated central artery that carried cars and trucks through the city. A massive eighteen-billion dollar infrastructure project, the "Big Dig," essentially sunk the highway and turned what had once been under the elevated highway into an urban park: the Rose Kennedy Greenway. That space has now become prime urban land, which is cherished both by pedestrians and by developers. The conflict between foot traffic and skyward construction has become a public policy battle, where public officials, especially the late Mayor Menino, have repeatedly opposed projects that would cast a shadow on the Greenway. Are strict height limitations justified in this prime downtown location? The benefits of tall buildings are relatively straightforward. ${ }^{31}$ There are costs that could presumably be quantified from added congestion and extra burdens on public services. Yet the cost that has received the most attention in this case is the lost amenity of light on the Greenway.

Loss of light has been a critical justification for zoning codes since the huge mass of the Equitable Building helped justify New York City's 1916 Zoning Ordinance. Yet there has been almost no work quantifying the welfare losses from lost light. When it comes to building residents, hedonics can help quantify the value destroyed from lost views. Space within buildings is sufficiently homogenous so that the prices at the top and bottom of buildings provides a reasonable estimate of the market value of clear sight lines (Glaeser et al. (2005a)).

Yet Mayor Menino was clearly worried about the costs that shadows impose on pedestrians, and we have close to no evidence on the values that pedestrians place on light amenities.

One contingent valuation approach in this setting would be to ask Bostonians to show Bostonians two images of the Greenway - one with the status quo and a second with a space of new buildings - and to ask them which they prefer, and how much they would be willing to pay per year to have their preferred streetscapes. This approach is likely to suffer from both non-instrumental answers and non-familiarity. Among those people who oppose development, images with shorter buildings would conform with identities as preservers of the status quo. Non-familiarity may be less extreme than in the case coastline cleanup—but still, few people have ever literally had the power to determine a streetscape. A decision involving trading height for cash is not one that respondents will have made in the past.

\footnotetext{
${ }^{31}$ The most obvious benefit is just the difference between the price of added space and the cost of building upwards. There could be ancillary benefits from agglomeration benefits and increased property tax revenues.
} 
A second alternative is to focus on the act of walking along the street. Respondents can be asked whether

they would rather walk along one streetscape or another. Then instead of asking whether they would pay for their preferred streetscape with cash, they can be asked whether they would be willing to walk some extra distance (one block, two blocks) so that they can amble along their preferred streetscape. This phrasing would not entirely eliminate non-instrumental voting. Supporters of a "shorter city" would presumably still understand the significance of the question and they may well want to assert their affection for the shorter building by giving a particularly high willingness to pay. However, the phrasing would still move the question completely into the realm of the familiar. Every urban resident has thought about their preferred routes and has occasionally weighed a shorter route against a more pleasant one. The one remaining step would be to turn the time willingness-to-pay into a cash willingness-to-pay.

A third alternative would be to quantify willingness-to-pay in terms of comparable urban amenities, such as open spaces and parks. The city could, in principle, use the value generated by building up around the Greenway to either upgrade or build new public spaces within the city. The respondents could be asked about their willingness to trade taller buildings off against new small urban parks. These parks could be made familiar by showing pictures of existing parking lots which could presumably be bought and turned into parks. Images of the potential park could then be offered. The respondent would then be trading likes against likes and there would be less of a non-instrumental reason to show high values for restricting building height along the Greenway.

\section{The Bedford Historic District}

The New York City Landmarks Commission is currently considering creating a historic district in Bedford, which is part of the Bedford-Stuyvesant neighborhood in Brooklyn. If the area's eight hundred buildings become part of a historic district, then the Landmarks Preservation Commission must approve any changes to the exteriors of buildings. While New York, like many other cities, has aggressively landmarked buildings for fifty years, neither the costs nor the benefits of this policy are particularly clear.

The primary costs are borne by property owners who lose freedom to change their structures. There are presumably also benefits that accrue to property owners, if having historic neighbors yields positive externalities. There may also be general equilibrium price effects coming from the reduction in housing supply in the city, which hurt prospective residents. These consequences are difficult to assess, but economics can in principle estimate these benefits.

Standard economic analysis, however, has few or no tools for assessing the benefits enjoyed by ordinary pedestrians who walk through historical districts, or the benefits enjoyed by urbanites who just like having historic districts exist. Again, this would seem to be an area in which contingent valuation offers the only means of estimating willingness to pay. Moreover, since preservation decisions are frequent, it would be 
impossible to consider having regular city-wide referenda on each and every historic district.

The broad model we propose is similar to those discussed above. Again, we would suggest an array of survey instruments. The first just asks about willingness to pay for the preservation of the area using the best available contingent valuation techniques. Again, we believe that this approach provides a useful benchmark, but faces both non-familiarity and non-instrumental survey response issues. The instrument we suggest is to use a time metric to assess pedestrian values. The streets of the Bedford Historic District can be compared with streets that have mixtures of old and new buildings. ${ }^{32}$ Respondents can be asked about willingness to walk to get their preferred streetscape at different times of the day or week; this time the comparison is familiar, although it does risk non-instrumental answers. The third instrument we suggest would compare the Bedford Historic District renovation with other investments in the city's physical past. ${ }^{33}$ Respondents could be asked about their tradeoffs between creating the Historic District in Bedford and specific investments in the city's past that come at different price tags. The alternative investment's costs would not be quantified, but they could be illustrated with artist's renderings and descriptions. This comparison would perhaps be unfamiliar, but it would be unlikely to suffer from non-instrumental responses. Finally, the Beford Historic district can be compared against scholarships for poor and middle-income New Yorkers. ${ }^{34}$

\section{Quantification and City Policy}

Beyond its value for urban science, improvements in the quantification of cities can dramatically change the way that cities operate and evaluate policies.

New big data sources with bearing on city policy are becoming abundant: governments are digitizing and sharing records, and private firms are collecting high-frequency measurements of local businesses, traffic, and other urban features. Some urban policy questions rely on concrete understanding of a causal effectand while big data can inform these questions, the associated analyses are subject to all of the identification caveats we discussed in Section 2. Other policies, however, can be informed directly through data, often in combination with predictive algorithms.

In this section, we develop a taxonomy of the new types of urban data now available to researchers and policymakers. We then discuss how the new data can impact policy.

\footnotetext{
${ }^{32}$ Ideally, an area that was considered for a historic district but did not receive the designation and subsequent was altered would provide alternative streetscapes.

${ }^{33} \mathrm{New}$ York has an abundance of abandoned and decaying landmarks, such as Staten Island's Abraham Manee House or the Old Bronx Borough Courthouse (http://ny.curbed.com/archives/2015/05/28/whats_next_for_new_ york_citys_many_abandoned_landmarks.php).

${ }^{34}$ Once again, this metric is imperfect as it suffers from both non-familiarity and non-instrumental forces, but it seems like an important alternative to try. At the least, it can show the power of different civic identities to shape contingent valuation responses.
} 


\section{A Taxonomy of Data Sources}

\section{Digital Exhaust}

One valuable but underutilized source of data is digital exhaust, the trail of data left online through everyone's day-to-day use of the Internet. Across a variety of domains, digital exhaust can help to measure the physical city. Review platforms such as Yelp and TripAdvisor provide direct measures of the quality of services and establishments throughout cities worldwide. Social media platforms such as Twitter and Facebook can inform us about the pulse of neighborhoods, or about the structure of social networks. LinkedIn can shed new light on labor markets and search costs. ${ }^{35}$ Search queries from platforms such as Google and Bing contain insight about the needs and preferences of a physical city. Zillow provides new insight into housing markets, as does data from sharing platforms such as Airbnb.

Digital exhaust data can be applied to city management directly: Yelp reviews, for example, provide detailed, high-frequency data on restaurants that can be used to assess hygiene (see the extended example discussed below, as well as Kang et al. (2013) and Glaeser et al. (forthcoming)). Google searches can be used to help predict flu outbreaks (see, e.g., Polgreen et al. (2008); Carneiro and Mylonakis (2009); Ginsberg et al. (2009)).

\section{Open Government Records}

Thirty years ago, cities kept most of their records on paper. Now, a growing digitization movement seeks to convert data that was historically on paper to electronic, machine-readable records. Digitized records are often made available online. For example, criminal records have been publicly available for several decades in many states, yet were very difficult for policymakers and researchers-much less the public-to access. Over time, criminal records have slowly become digitized and readily available; this has made research easier, but also has also influenced incentives for recidivism and criminal behavior more generally (Finlay (2009); Luca (forthcoming)).

An "open data" movement seeks to increase transparency by making cities' internal data publicly available. Many large cities (e.g., Boston, Chicago, and San Francisco) have created open, freely accessible "data portals" that researchers and citizens can use to access digitized records; many of these data portals are updated in real-time. The availability of open data encourages entrepreneurs to look for ways in which city data can be used to enhance welfare, and creates possibilities for new partnerships between city officials and researchers.

\footnotetext{
${ }^{35}$ For an overview of these and other user-generated content platforms, see Luca (2015).
} 


\section{Corporate Data}

Private data from companies represents a third, less developed, approach to measuring the physical city. In addition to the digital data mentioned above, one can imagine using gym memberships to understand health behavior, College Board data to gain additional insight into student performance, and credit card transactions to quantify changes in spending over time.

\section{How can new data empower the city?}

At a basic level, cities specialize in three activities that are deeply reliant on—or can be greatly improved through—data and analysis.

1. Cities evaluate and enact policies and regulations.

2. Cities operate public services.

3. Cities forecast future activity for the sake of planning and policymaking.

Here, we briefly sketch how big data will influence each of these activities.

\section{Policy Evaluation}

At a basic level, policy evaluations help to understand the intended and unintended consequences of policies. Yet, most empirical analyses look at very narrow outcomes. We might examine, for example, at the impact of hotel tax rates on the prices of hotels. We would prefer to measure the broader impact of taxes, but historically, other factors such as the impact of taxes on "quality" would be very difficult to measure. Now, we can in principle combine tax changes with TripAdvisor ratings, Priceline prices, and Airbnb listings to obtain a much broader view of the intended and unintended consequences of tax policy on the physical city. In addition to broadening the outcomes under consideration, new data can lead to higher-frequency estimates

of changes. Suppose, for example that we want to evaluate the impact of unemployment benefits on job searches. Traditional analyses might look at length of unemployment and average income after one year. But LinkedIn and similar sites could in principle give us measures of day-by-day job search behavior.

\section{Operating Public Services}

While research has traditionally focused on policy evaluations, there is a growing acknowledgment of the practical importance of prediction problems. Cities, for example, are responsible for allocating scarce resources. Cities choose which domestic violence cases to follow up on, and which labor market complaints to investigate; in both of these settings underlying choice problem here is not a program or evaluation, but 
rather a prediction problem. The city must predict which domestic violence offenders are likely to reoffend, and which labor market complaint is most likely to unearth a serious issue. Using data to improve these predictions about the physical city creates value-and new data sources are central to this task (see Kleinberg et al. (2015)).

\section{Forecasting}

Urban planners and policymakers forecast future economic activity through time-series analyses on leading indicators of activity. New data sources—especially coupled with machine learning-have the potential to revolutionize forecasting. Zillow, TripAdvisor, and LinkedIn, for example, respectively provide measurements that can be used in estimating future housing prices, tourism, and unemployment. Data from app-based payment systems can provide insight into upcoming retail spending and consumption patterns.

\section{Closing Example: Data-Driven Hygiene Inspections}

We close this section with an applied example showing how data and predictive tools can directly inform city resource allocation.

In nearly every developed country, health inspectors examine restaurants to identify unsafe restaurant practices (such as storing food at unsafe temperatures), which can lead to foodborne illness. These inspectors are typically allocated according to the perceived health risk posed by a restaurant or cuisine. A sushi restaurant may be inspected more often than a burger joint because sushi is more likely to lead to food sickness. Other than that, health inspector allocation is effectively random.

But inspections do not have to be random. Suppose instead that you were to base the likelihood of inspection on evidence from Yelp reviews. Perhaps you would start with a search on Yelp for terms like "sick" or "dirty"; you would probably find a few culprits. But a predictive algorithm trained through machine learning can do much more than that. The algorithm would "learn" from the history of reviews and history of inspection outcomes, and then predict the likelihood of finding violations based on more recent reviews. Inspectors could then be reallocated to restaurants that are most likely to have violations.

Kang et al. (2013) and Glaeser et al. (forthcoming) explored the feasibility of doing exactly that, using natural language processing to predict hygiene violations using reviews on Yelp. To see how powerful even a simple adjustment can be, consider Figure 3, which shows the correlation between Yelp ratings and hygiene scores. Even before applying machine-learning techniques, it is clear that Yelp scores can help to identify hygiene scores. In a competition run with the city of Boston to develop a predictive algorithm for Boston, Glaeser et al (forthcoming) demonstrated that using Yelp reviews to guide inspections would allow 


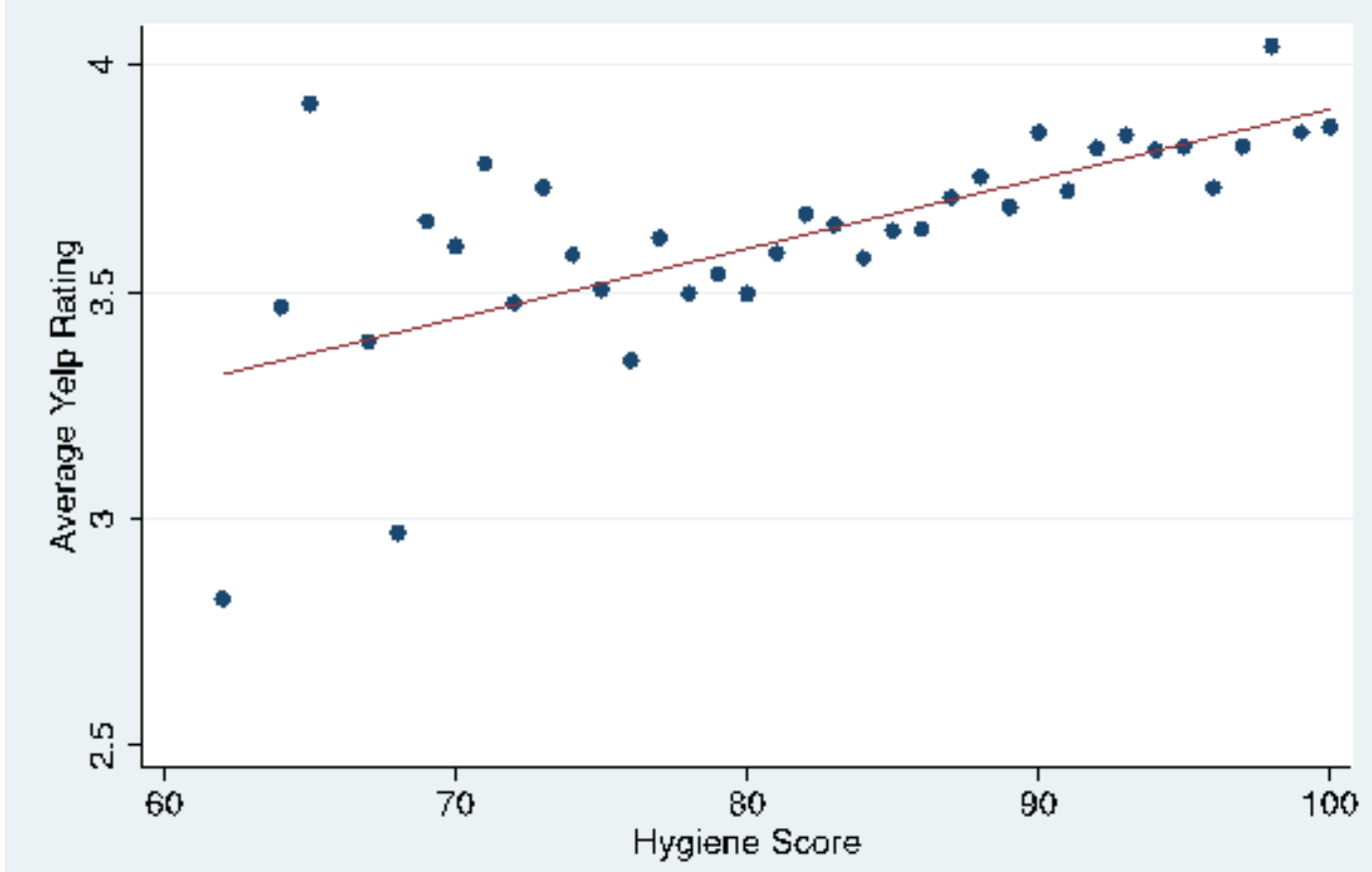

- Rating Fitted values

Figure 3: Correlation between Yelp Ratings and Hygiene Inspection Scores

Review data consists of reviews on Yelp.com for restaurants in San Francisco, CA from September, 2010 through September, 2013. Hygiene scores consist are from the San Francisco Department of Public Health, for the same timeframe. 
reducing inspections by $40 \%$ without reducing the number of health risks identified. ${ }^{36}$

\section{Conclusion}

This paper has reviewed ways in which big data and new measurement can improve urban research and policymaking.

There are research areas in which measurement is itself the barrier, and those areas are readily improved through big data aggregation and analysis. For example, in Section 3, we discussed the use of Google Street View to measure income. We showed that images do well at predicting income in New York City. If images are also effective for predicting income in the developing world (based, for example, on small-scale surveys), then they can enable us to map out the income and to measure whether exogenous shocks shape income, at least as reflected in the streetscape.

Urban social scientists should also continue pushing for more targeted data gathering. Section 4 discussed contingent valuation surveys, which, while typically used in environmental contexts, have value for urban policy-making as well. The key here is to use insights from psychology to lead respondents to report valuations that make sense. For example, pure money-metric questions, such as "How much is central park worth for you?" seem likely to produce near-valueless answers. A better approach is to make comparisons within-domain, for example, comparing investments in parks to investments in road quality. Also, surveyors should strive to ask questions that deal with tradeoffs people routinely make in their daily lives (e.g., "Are you willing to walk a block or two to travel down a street with shorter buildings?").

Big data is particularly valuable when it can improve policymaking directly. Section 5 discussed the ways in which Yelp (and other crowdsourced rating tools) can augment city services such as inspections. More generally, big data offers the ability to use the broader civil society to augment the functions of government, essentially by lowering the costs of contributing to government services. Electronic "apps" and similar provide tools that citizens can use to give feedback to governments quickly and inexpensively.

In general, big data can meaningfully help big cities and improve research on cities—but only if it is used with thoughtful care. Big data will do far more for urban research if it is paired with exogenous sources of variation. Big data will do far more for policymaking and implementation if it is paired with openness to new methods. As in most areas, new technology works best if it is accompanied by human capital.

\footnotetext{
${ }^{36}$ Urban economists can also use prediction algorithms to improve their analyses. For example, Jin and Leslie (2003) look at the impact of mandatory disclosure of hygiene grades on restaurant cleanliness; they show that independent and chain restaurants have systematically different hygiene grades. Because each restaurant is inspected only a few times per year, any analysis of the Jin and Leslie (2003) type needs to wait for new inspections to be performed. One could instead run the Jin and Leslie (2003) analysis using the predicted hygiene as a dependent variable, as determined by Yelp reviews.
} 


\section{References}

Akerlof, G. A. and R. E. Kranton (2000). Economics and identity. Quarterly Journal of Economics 115(3), $715-753$.

Arrow, K., R. Solow, P. R. Portney, E. E. Leamer, R. Radner, and H. Schuman (1993). Report of the NOAA panel on contingent valuation.

Arzaghi, M. and J. V. Henderson (2008). Networking off Madison Avenue. Review of Economic Studies 75(4), 1011-1038.

Autor, D. H., C. J. Palmer, and P. A. Pathak (2014). Housing market spillovers: Evidence from the end of rent control in Cambridge, Massachusetts. Journal of Political Economy 122(3), 661-717.

Baum-Snow, N. (2007). Did highways cause suburbanization? Quarterly Journal of Economics 122(2), 775-805.

Berry, C. R. and E. L. Glaeser (2005). The divergence of human capital levels across cities. Papers in Regional Science 84(3), 407-444.

Black, S. E. (1999). Do better schools matter? Parental valuation of elementary education. Quarterly Journal of Economics 114(2), 577-599.

Braga, A. A. and B. J. Bond (2008). Policing crime and disorder hot spots: A randomized controlled trial. Criminology 46(3), 577-607.

Busso, M. and P. Kline (2008). Do local economic development programs work? Evidence from the Federal Empowerment Zone Program. Cowles Foundation Discussion Paper No. 1638.

Caplan, B. (2011). The Myth of the Rational Voter: Why Democracies Choose Bad Policies. Princeton University Press.

Carneiro, H. A. and E. Mylonakis (2009). Google trends: A web-based tool for real-time surveillance of disease outbreaks. Clinical infectious diseases 49(10), 1557-1564.

Carson, R. T. and T. Groves (2007). Incentive and informational properties of preference questions. Environmental and Resource Economics 37(1), 181-210.

Chang, C.-C. and C.-J. Lin (2002). Training $v$-support vector regression: Theory and algorithms. Neural Computation 14(8), 1959-1977.

Chetty, R., N. Hendren, and L. F. Katz (2015). The effects of exposure to better neighborhoods on children: New evidence from the Moving to Opportunity experiment. NBER Working Paper No. 21156.

Ciccone, A. and R. E. Hall (1996). Productivity and the density of economic activity. American Economic Review 86(1), 54-70. 
Ciriacy-Wantrup, S. V. (1963). Resource Conservation: Economics and Policies. Univ of California Press.

Combes, P.-P., G. Duranton, and L. Gobillon (2008). Spatial wage disparities: Sorting matters! Journal of Urban Economics 63(2), 723-742.

Combes, P.-P., G. Duranton, L. Gobillon, and S. Roux (2010). Estimating agglomeration effects with history, geology, and worker effects. In E. L. Glaeser (Ed.), Agglomeration Economics, pp. 15-65. University of Chicago Press.

Currie, J. and R. Walker (2011). Traffic congestion and infant health: Evidence from E-ZPass. American Economic Journal: Applied Economics 3(1), 65-90.

Davis, R. K. (1963). Recreation planning as an economic problem. Natural Resources Journal 3(3), 239249.

Desvousges, W. H., F. R. Johnson, R. W. Dunford, K. J. Boyle, S. P. Hudson, and K. N. Wilson (1993). Measuring natural resource damages with contingent valuation: Tests of validity and reliability. In J. A. Hausman (Ed.), Contingent Valuation: A Critical Assessment, Contributions to Economic Analysis, pp. 91-164. North Holland Press.

Diamond, P. A. and J. A. Hausman (1994). Contingent valuation: Is some number better than no number? The Journal of Economic Perspectives 8(4), 45-64.

Dwork, C. and A. Roth (2013). The algorithmic foundations of differential privacy. Theoretical Computer Science 9(3-4), 211-407.

Epple, D. (1987). Hedonic prices and implicit markets: Estimating demand and supply functions for differentiated products. Journal of Political Economy 95(1), 59-80.

Finlay, K. (2009). Effect of employer access to criminal history data on the labor market outcomes of exoffenders and non-offenders. In D. H. Autor (Ed.), Studies of Labor Market Intermediation, pp. 89-125. University of Chicago Press.

Ginsberg, J., M. H. Mohebbi, R. S. Patel, L. Brammer, M. S. Smolinski, and L. Brilliant (2009). Detecting influenza epidemics using search engine query data. Nature 457(7232), 1012-1014.

Glaeser, E. and D. Maré (2001). Cities and skills. Journal of Labor Economics 19(2), 316-342.

Glaeser, E. L. and J. D. Gottlieb (2008). The economics of place-making policies. Brookings Papers on Economic Activity 39(1), 155-239.

Glaeser, E. L., J. Gyourko, and R. E. Saks (2005a). Why have housing prices gone up? American Economic Review 95(2), 329-333. 
Glaeser, E. L., J. Gyourko, and R. E. Saks (2005b). Why is Manhattan so expensive? Regulation and the rise in housing prices. Journal of Law and Economics 48(2), 331-369.

Glaeser, E. L., E. A. Hanushek, and J. M. Quigley (2004). Opportunities, race, and urban location: The influence of John Kain. Journal of Urban Economics 56(1), 70-79.

Glaeser, E. L., A. Hillis, S. D. Kominers, and M. Luca (forthcoming). Crowdsourcing city government: Using tournaments to improve inspection accuracy. American Economic Review Papers \& Proceedings.

Gramlich, E. M. (1994). Infrastructure investment: A review essay. Journal of Economic Literature 32, 1176-1196.

Greenstone, M., R. Hornbeck, and E. Moretti (2010). Identifying agglomeration spillovers: Evidence from winners and losers of large plant openings. Journal of Political Economy 118(3), 536-598.

Gregoir, S., M. Hutin, T.-P. Maury, and G. Prandi (2012). Measuring local individual housing returns from a large transaction database. Annals of Economics and Statistics (107/108), 93-131.

Hausman, J. A. (2012). Contingent valuation: From dubious to hopeless. Journal of Economic Perspectives 26(4), 43-56.

Hoiem, D., A. A. Efros, and M. Hebert (2008). Putting objects in perspective. International Journal of Computer Vision 80(1), 3-15.

Holmes, T. J. (1998). The effect of state policies on the location of manufacturing: Evidence from state borders. Journal of Political Economy 106(4), 667-705.

Jin, G. Z. and P. Leslie (2003). The effect of information on product quality: Evidence from restaurant hygiene grade cards. Quarterly Journal of Economics 118(2), 409-451.

Johnson, B. K. and J. C. Whitehead (2000). Value of public goods from sports stadiums: The CVM approach. Contemporary Economic Policy 18(1), 48-58.

Kahneman, D. and J. L. Knetsch (1992). Valuing public goods: The purchase of moral satisfaction. Journal of Environmental Economics and Management 22(1), 57-70.

Kang, J. S., P. Kuznetsova, M. Luca, and Y. Choi (2013). Where not to eat? Improving public policy by predicting hygiene inspections using online reviews. In Proceedings of the Conference on Empirical Methods in Natural Language Processing, pp. 1443-1448. Citeseer.

Katz, L. F., J. R. Kling, and J. B. Liebman (2001). Moving to Opportunity in Boston: Early results of a randomized mobility experiment. Quarterly Journal of Economics 116, 607-651.

Kho, A. N., J. P. Cashy, K. L. Jackson, A. R. Pah, S. Goel, J. Boehnke, J. E. Humphries, S. D. Kominers, B. N. Hota, S. A. Sims, B. A. Malin, D. D. French, T. L. Walunas, D. O. Meltzer, E. O. Kaleba, R. C. 
Jones, and W. L. Galanter (forthcoming). Design and implementation of a privacy preserving electronic health record linkage tool in Chicago. Journal of the American Medical Informatics Association.

Kleinberg, J., J. Ludwig, S. Mullainathan, and Z. Obermeyer (2015). Prediction policy problems. American Economic Review 105(5), 491-495.

LeDuc, L. (2003). The Politics of Direct Democracy: Referendums in Global Perspective. Broadview Press.

Luca, M. (forthcoming). User-generated content and social media. In S. Anderson, J. Waldfogel, and D. Stromberg (Eds.), Handbook of Media Economics. Elsevier.

Malik, J., S. Belongie, T. Leung, and J. Shi (2001). Contour and texture analysis for image segmentation. International Journal of Computer Vision 43(1), 7-27.

Matsusaka, J. G. (2005). Direct democracy works. Journal of Economic Perspectives 19(2), 185-206.

Moretti, E. (2004). Human capital externalities in cities. In G. Duranton, J. V. Henderson, and W. C. Strange (Eds.), Handbook of Regional and Urban Economics, Volume 4, pp. 2243-2291. Elsevier.

Naik, N., S. D. Kominers, R. Raskar, E. L. Glaeser, and C. A. Hidalgo (2015). Do people shape cities, or do cities shape people? The co-evolution of physical, social, and economic change in five major US cities. NBER Working Paper No. 21620.

Naik, N., J. Philipoom, R. Raskar, and C. A. Hidalgo (2014). Streetscore - predicting the perceived safety of one million streetscapes. In IEEE Computer Vision and Pattern Recognition.

Newman, O. (1972). Defensible Space. Macmillan New York.

Oliva, A. and A. Torralba (2001). Modeling the shape of the scene: A holistic representation of the spatial envelope. International Journal of Computer Vision 42(3), 145-175.

Persson, P.-O. and G. Strang (2004). A simple mesh generator in MATLAB. SIAM review 46(2), 329-345.

Pew Research Center (2014). Millenials in adulthood: Detached from institutions, networked with friends. http://www.pewsocialtrends.org/files/2014/03/2014-03-07_ generations-report-version-for-web.pdf.

Polgreen, P. M., Y. Chen, D. M. Pennock, F. D. Nelson, and R. A. Weinstein (2008). Using internet searches for influenza surveillance. Clinical Infectious Diseases 47(11), 1443-1448.

Rauch, J. E. (1993). Productivity gains from geographic concentration of human capital: Evidence from the cities. Journal of Urban Economics 34(3), 380-400.

Roback, J. (1982). Wages, rents, and the quality of life. Journal of Political Economy 90(6), 1257-1278.

Rosen, S. (1979). Wage-based indexes of urban quality of life. In P. Miezkowski and M. R. Straszheim (Eds.), Current Issues in Urban Economics, Volume 3. Johns Hopkins University Pres. 
Salesses, P., K. Schechtner, and C. A. Hidalgo (2013). The collaborative image of the city: Mapping the inequality of urban perception. PloS one 8(7), e68400.

Sampson, R. J., S. W. Raudenbush, and F. Earls (1997). Neighborhoods and violent crime: A multilevel study of collective efficacy. Science 277(5328), 918-924.

Schölkopf, B., A. J. Smola, R. C. Williamson, and P. L. Bartlett (2000). New support vector algorithms. Neural Computation 12(5), 1207-1245.

Schrag, P. (2004). Paradise Lost: California's Experience, America's Future. University of California Press.

Weiss, M. (2015). More citizens connect. Harvard Business School Case 315-075. 